\section{Zosteriform morphea: Wolf's isotopic response in an immunocompetent patient}

\author{
Ricardo Ruiz-Villaverde, ${ }^{1}$ \\ Daniel Sánchez-Cano, ${ }^{2}$ \\ Manuel Galán-Gutiérrez ${ }^{1}$ \\ 'Dermatology Dept., Complejo \\ Hospitalario de Jaen, Jaen; \\ ${ }^{2}$ Internal Medicine Dept., Hospital Santa \\ Ana, Motril, Granada, Spain
}

\section{Abstract}

We report the case of a 19-year old female who presented to our dermatological clinic with hyperpigmented, indurated and atrophic patches on a zosteriform distribution, extending from her left submammary region through to her back. Our case was consistent with a zosteriform morphea as an expression of an isotopic Wolf response following an episode of herpes zoster. We discuss the pathogenic mechanisms and review the clinical cases previously reported in the literature.

\section{Case Report}

A 19-year old female presented to our dermatological clinic with hyperpigmented, indurated and atrophic patches on a zosteriform distribution extending from her left submammary region (Figure 1) through to her back (Figure 2). No erythema could be observed either in or around the lesions. The patient denied any personal or family past medical history of interest, except for an episode of herpes zoster on the same location two years before. Clinical examination did not reveal any other cutaneous lesions. Blood cell count, general biochemistry, urinalysis, thyroid profile, antinuclear antibodies, erythrocyte sedimentation rate, $\mathrm{C}$ reactive protein, chest X-ray and serological tests for Borrelia burgdoferi showed no abnormalities. Serology for varicella-zoster virus tested negative for IgM but positive for IgG.

Histopathological examination showed thick bundles of collagen in reticular dermis orientated parallel to the skin surface. Cutaneous appendages were reduced. A perivascular inflammatory infiltrate composed of plasma cells and lymphocytes could also be observed. Thus, our case was consistent with zosteriform morphea as an expression of isotopic Wolf response following an episode of herpes zoster. The patient was then started on a calcipotriol/betamethasone gel, with only a mild therapeutic response.

The term zosteriform is commonly used to describe the morphological pattern of a skin dermatosis resembling the distribution of herpes zoster. Lichen planus, porokeratosis, common warts, fungal infections, naevus and skin metastases are some of the conditions that have been described as following this pattern. On the other hand, several types of cutaneous lesions have previously been described at the site of herpes zoster scars. ${ }^{1}$ This phenomenon, which is characterized by the occurrence of a new skin condition at the site of a previous one, was named isotopic response by Wolf et $a l^{2}$ Even though the cutaneous eruptions described in herpes zoster scars are variable, granuloma annulare and other types of granulomatous disorders are the most commonly reported reactions. Zosteriform morphea has rarely been described after herpes zoster in immunocompromised $^{3,4}$ or immunocompetent ${ }^{5}$ patients. It has been hypothesized that the viral infection might change local immunity, thus inducing a delayed-type hypersensitivity reaction to herpes zoster viral antigen or an immune suppression. We agree with Lopez et

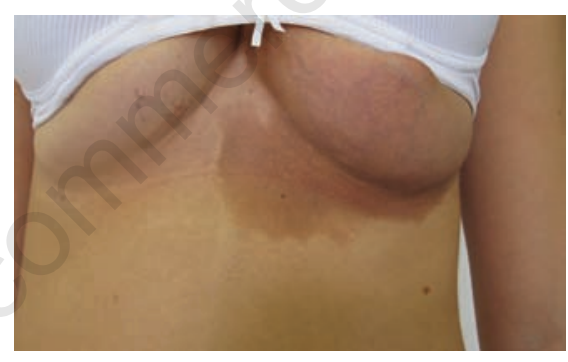

Figure 1. Hyperpigmented patch on a zosteriform distribution on the submammary region.

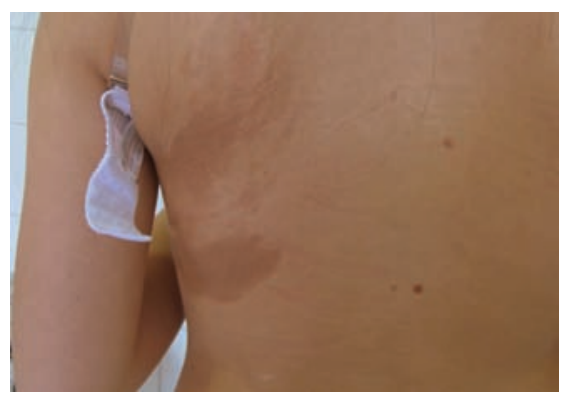

Figure 2. Morphea lesions on the back completing the zosteriform pattern.
Correspondence: Ricardo Ruiz Villaverde, Dermatology Department, Complejo Hospitalario de Jaen, avda. Ejército Español s.n., 23007 Jaen, Spain. Tel. +34.963.008.000.

E-mail: ismenios@hotmail.com

Key words: zosteriform morphea.

Received for publication: 15 July 2011.

Revision received: 5 August 2011.

Accepted for publication: 5 August 2011.

This work is licensed under a Creative Commons Attribution NonCommercial 3.0 License (CC BYNC 3.0).

(C) Copyright R. Ruiz-Villaverde et al., 2011

Licensee PAGEPress, Italy

Dermatology Reports 2011; 3:e16

doi:10.4081/dr.2011.e16

$a l .{ }^{6}$ that a different dermatosis can be expressed according to the cytokine pattern of the inflammatory response. Conversely, it is to be remembered that other conditions, such as zosteriform lichen planus, have been interpreted as a manifestation of Koebner's phenomenon. This pattern would be an expression of a viscerocutaneous reflex mechanism within the affected segments consequent to a radicular irritation caused by abnormalities in the spine. Nevertheless, further studies are needed to better interpret Wolf's isotopic response.

\section{References}

1. Requena L, Kutzner H, Escalonilla P, et al. Cutaneous reactions at sites of herpes zoster scars: an expanded spectrum. Br J Dermatol 1998;138:161-8.

2. Wolf R, Brenner S, Ruocco V, et al. Isotopic response. Int J Dermatol 1995;34:341-8.

3. Zimmermann H. Zoster als Prämorbid einer zirkumskripten sklerodermie. Dermatol Wochenschr 1964;150:112-6.

4. Forschner A, Metzler G, Rassner G, et al. Morphea with features of lichen sclerosus et atrophicus at the site of a herpes zoster scar: another case of an isotopic response. Int J Dermatol 2005;44:524-5.

5. Joshi A, Al-Mutairi N. Zosteriform morphea: a new pattern. Acta Derm Venereol 2005;85:279-80.

6. López N, Alcaraz I, Cid-Mañas J, et al. Wolf's isotopic response: zosteriform morphea appearing at the site of healed herpes zoster in a HIV patient. J Eur Acad Dermatol Venereol 2009;23:90-2. 